\section{IMPLEMENTATION OF THE} DESIGNED PROGRAM FOR CALCULATION AND CHECK OF CHAIN GEARS JOZEF MASCENIK

Department of Design and Monitoring of Technical Systems, Faculty of Manufacturing Technologies with a seat in Presov, Technical University of Kosice, Presov Slovak republic

DOI : 10.17973/MMSJ.2019_12_2019008

jozef.mascenik@tuke.sk

The presented paper deals with the design proposal and application of program for calculation and check of chain gears. The computing program has been created as a spreadsheet in the working environment of the Microsoft Office program by the Excel application through defined sequences of the individual commands. The program serves for design proposal of a chain drive by means of inserted databases, graphs and tables. In the process of designing and checking the input values are entered such as performance, rotations, and number of wheels. Through calculation the software generates speed of a chain, circumferential speed, tensile force, number of chain links, axial distance, etc. At the same time the paper compares generated parameters with manual calculation of the chain gear.

KEYWORDS

program, chain gears, calculation, design, strength

\section{INTRODUCTION}

Transmission of kinematic and force effects of the driving engine upon working machine is provided by the drive. The overall structure of the drive does not represent the simplest part; the entire drive consists of several segments. The segments are jointly exposed to stress and therefore the segments are overloaded and damaged. Or some of its segments get worn. All of the aforementioned reasons lead to correct specification of drive structure and to designing of its individual segments to assure reliable operation which would be safe and economical. The chain drive also consists of several segments which must work together in perfect harmony [Murcinkova 2013]. In case of incorrect coherence of the segments the gear would be ineffective and eventually unusable. In practice the chain drive is exposed to effects of environment which influences the chain. Appropriate care and maintenance of the chain gear as well as adequate servicing can prolong its service life. Even though current market offers diverse programs which can design chain gears and carry out strength analysis still there exists platform for improvement and creation of such programs [Gaspar 2017].

\section{CHAIN GEARS}

Chain gears are as machine parts which are used for transmission of low and average performance with circumferential speed of up to 30 or $45 \mathrm{~m} . \mathrm{s}^{-1}$ in case of which the gear ratio reaches values of $i=$ from 2 up to 8 , from a driving shaft to a shaft or to several shafts serving for transmission of torque $M_{k}$. One of the simplest chain gears is a gear which consists of a chain and of two chain wheels [Smeringaiova 2016].

Generally valid regularities of gears are applicable in case of chain gears therefore gear ratio is as follows:

$$
\mathrm{i}=\frac{\omega_{1}}{\omega_{2}}=\frac{\mathrm{n}_{1}}{\mathrm{n}_{2}}=\frac{\mathrm{z}_{2}}{\mathrm{z}_{1}}, \quad \text { or } \quad i=\eta * \frac{M_{2}}{M_{1}}
$$

Alike the belt gear the chain gears are based on transmission of tensile force. They perform rotary motions between two or among several shafts. The chains are mostly made of premium steel which and therefore their strength and compactness is higher contrary to belts [Pavlenko 2017b].

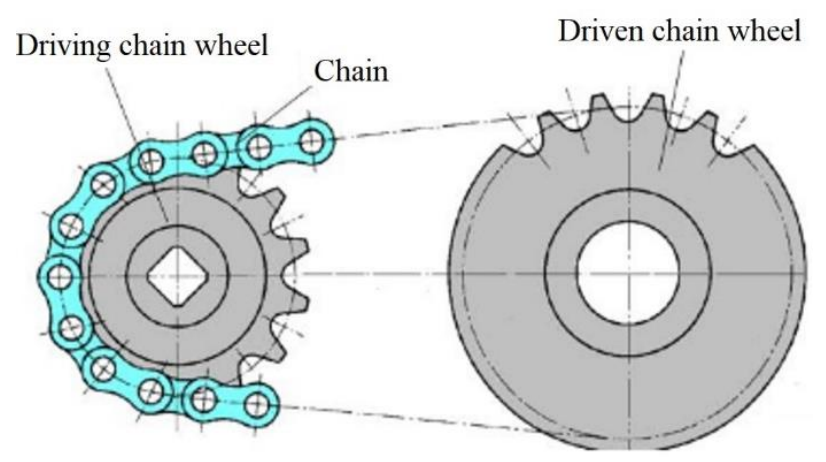

Figure 1. Chain gear and its main parts

Chain gear can transmit large tensile force for long distance; it is also synchronous with invariable gear ratio, i.e. without slip. The gears are immune to negative influences of environment and therefore they are used, for example, in case of shaping machines, conveyor belts, bicycles and motorcycles, construction machines and automobiles [Mascenik 2014].

\section{ANALYTICAL CALCULATION OF CHAIN GEAR}

To assure correct results of the designed program the program out was compared with the results of analytical calculation. To provide comparison the following mathematical model of design proposal and check of chain gear was proposed:

Input performance $P=8.5 \mathrm{~kW}$, input rotations $\mathrm{n}_{1}=2.316 \mathrm{~s}^{-1}$.

\subsection{Design Proposal of Chain Gear}

Calculation of diagram performance:

$$
P_{D}=\frac{P}{\kappa * \mu * \varphi}=\frac{8.5}{0.82 * 1 * 0.6}=17.66 \mathrm{~kW}
$$

To determine the suitable chain, the diagram performance $P_{D}$ and rotations of output shafts are followed. Trough calculation by means of graph (Fig.2) intended for determination of the chain drive selected is the triple-line chain 16B-3 STN 023311 standard and selected are also $\mathrm{z}_{1}=15$ and $\mathrm{z}_{2}=30$ [Pavlenko 2015].

Calculation of Pitch Diameters:

$$
\begin{aligned}
& D_{t 1} \frac{t}{\sin \frac{180^{\circ}}{z_{1}}}=\frac{25.4}{\sin \frac{180^{\circ}}{15}}=122.167 \mathrm{~mm} \\
& D_{t 2}=\frac{t}{\sin \frac{180^{\circ}}{z_{2}}}=\frac{25.4}{\sin \frac{180^{\circ}}{30}}=243.06 \mathrm{~mm}
\end{aligned}
$$

With $\mathrm{t}$ - chain pitch, $\mathrm{z}_{1}$ - number of teeth of input wheel.

Type of chain $16 \mathrm{~B}$ was selected on the basis of the calculated value of diagram performance and input rotations by means of the following diagram (Fig.2). 


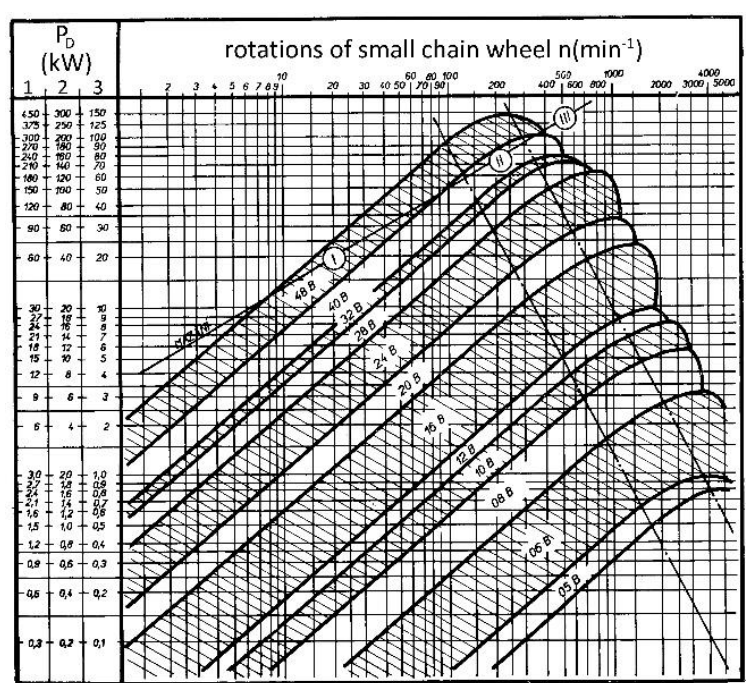

Figure 2. Diagram for selection of chain type

\subsection{Strength Check of a Chain}

Chain Speed:

$v=\frac{\pi * D_{t 1} * n_{1}}{1000}=\frac{\pi * 122.17 * 2.316}{1000}=0.888 \mathrm{~m} . \mathrm{s}^{-1}$

Circumferential speed of a chain wheel:

$$
F_{O}=\frac{P * 1000}{v}=\frac{8.476 * 1000}{0.888}=9545.045 \mathrm{~N}
$$

Circumferential force caused by the effect of centrifugal force:

$$
F_{o c}=m^{\prime} * v^{2}=8 * 0.888^{2}=6.23 \mathrm{~N}
$$

Overall tensile force of a chain:

$$
F_{t}=F_{o}+F_{o c}=9545.045+6.23=9551.27 \mathrm{~N}
$$

Calculation pressure in a joint of a chain:

$$
P_{P}=\frac{F_{t}}{S}=\frac{9551.27}{631}=15.136 \mathrm{MPa}
$$

Permitted pressure in the joint of a chain:

$P_{D}=p * \lambda \geq P_{P}$

$P_{D}=26.6 * 0.6=15.96 \mathrm{MPa}$

$\lambda$ - coefficient of friction

$$
\text { 15.96 MPa } \geq 15.136 \mathrm{MPa} \Rightarrow \text { satisfactory }
$$

Safety coefficient against rupture in case of static load:

$$
k_{s}=\frac{F_{p t}}{F_{p}} \geq 7 \Rightarrow \frac{181500}{9551.27}=19.002 \geq 7 \Rightarrow \text { satisfactory }
$$

Safety coefficient against rupture in case of dynamic load: $k_{s}=\frac{F_{p t}}{F_{p} * Y} \geq 5 \Rightarrow \frac{181500}{9551.27 * 1}=19.002 \geq 5 \Rightarrow$ satisfactory

Number of chain elements: $a=300 \mathrm{~mm}$ is selected

$X=2 * \frac{a}{t}+\frac{Z_{1}+Z_{2}}{2}+\left[\frac{Z_{2}-Z_{1}}{2 * \pi}\right]^{2} * \frac{t}{a}=2 * \frac{300}{25.4}+\frac{15+30}{2}+\left[\frac{30-15}{2 * \pi}\right]^{2} *$ $\frac{25.4}{300}=47.6 \Rightarrow 48$ elements are selected.

Actual axial distance

$$
\begin{aligned}
& a=\frac{25.4}{8} *\left[2 * 48-15-30+\sqrt{(2 * 48-15-30)^{2}}-\right. \\
& \left.F(30-15)^{2}\right]=247.65 m m a=\frac{25.4}{8} *[2 * 48-15-30+ \\
& \left.\sqrt{(2 * 48-15-30)^{2}}-F(30-15)^{2}\right]=247.65 m m
\end{aligned}
$$

\section{DESIGN OF A CALCULATION PROGRAM}

Designing of the program starts in the Excel environment through getting acquainted with the program environment and trough consequent implementation of descriptions and of cells, which are intended for entering the numerical values into program. Selection of suitable descriptions assures transparency during calculations and unnecessary mistakes in recording are thus avoided [Fabian 2014].

Implementation of all descriptions inevitable for the user, to be able to get oriented in the program easily, is followed by a part in case of which formulae must be entered into predetermined cells. Entering of the formulae represents rather significant part in program creation from the point of view of correct functioning of the program. As the figure shows, the formula consists of entered values which are needed for the calculation.

\subsection{Main Program}

The main program contains a series of calculations which are inevitable for calculation of the chain gear. The entire program is divided into two parts in the first one of which the chain gear is designed and in the second one of which the calculations related to strength checks of the chain are carried out.

\subsection{Design Part of the Program}

In case of design part, the entered values are filled into the cells such as performance, rotations of a small chain wheel, coefficient of performance, coefficient of greasing, coefficient of chain construction, coefficient of shock, gear ratio and number of teeth of a small wheel. According to the entered values the values of diagram performance are calculated, number of teeth of a big wheel and calculations of pitch diameters for both wheels [Cacko 2014, Mascenik 2016a].

The design part also contains a section for determination of values of the selected chain the values of which are necessary for the chain check.

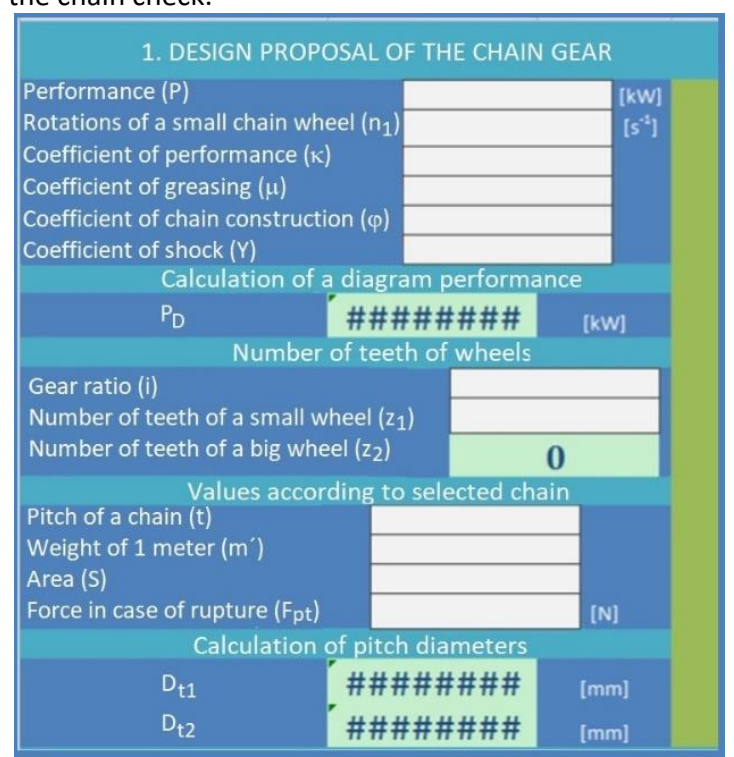

Figure 3. Design part of the program

\subsection{Checking Part of the Program}

The second part of the program is focused on strength check of the selected chain which must meet particular conditions to be put into practice. From this point of view, the chain is tested under diverse types of load. In the checking part the chain is tested. In the second part calculated is speed of chain, number of elements of the respective chain as well as its actual axial distance.

According to the entered and calculated values the program determines the values of circumferential force, of overall tensile force in the chain, calculation pressure in the joint of the chain, safety coefficient against rupture in case of static and dynamic loads. Permitted pressure in the joint is the value calculated out 
of the table values for decisive pressure and coefficient of friction.

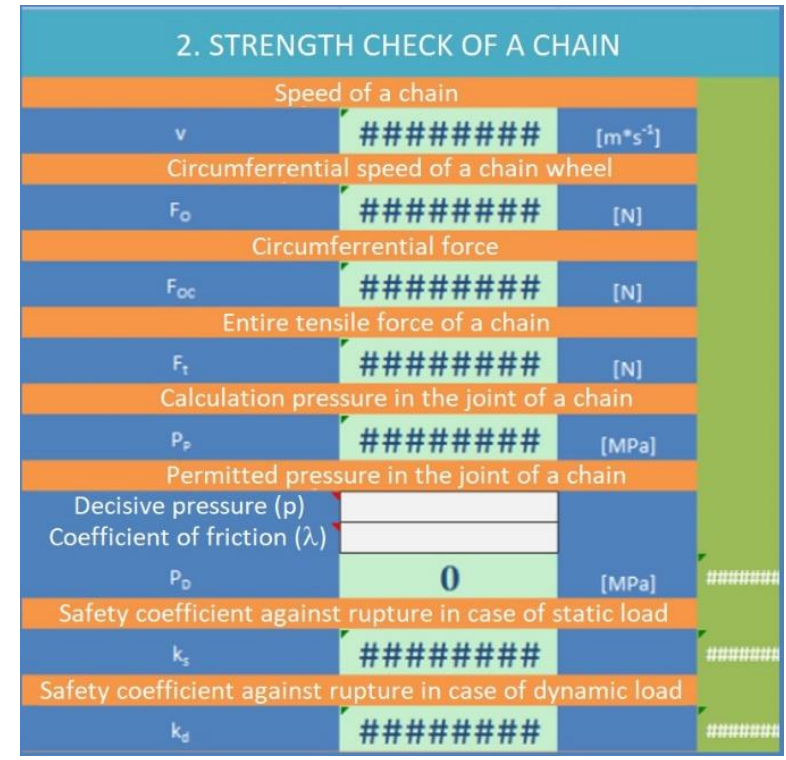

Figure 4. Strength check of the chain

For correct check of the chain it is inevitable to detect if the chain is suitable. The program also works with the comparison of the values which are consequently assessed. In case of unsuitable values, it immediately detects and assesses the value as being the suitable or unsuitable [Bicejova 2013].

The program compares calculation pressure with the permitted one. The permitted pressure should be higher than the calculation one [Majernik 2018].

\begin{tabular}{|c|c|c|}
\hline \multicolumn{3}{|c|}{ Calculation pressure in the joint of a chain } \\
\hline$P_{p}$ & 15.470 & [MPa] \\
\hline \multicolumn{3}{|c|}{ Permitted pressure in the joint of a chain } \\
\hline Decisive pressure (p) & 26.6 & \\
\hline Coefficient of friction $(\lambda)$ & 0.6 & \\
\hline$P_{0}$ & 15.96 & [MPa] \\
\hline
\end{tabular}

Figure 5. Suitable pressure

In case of unsuitable pressure, the program colours the cell red and assesses the pressure as the unsuitable one.

\begin{tabular}{|c|c|c|}
\hline \multicolumn{3}{|c|}{ Calculation pressure in the joint of a chain } \\
\hline$P_{p}$ & 15.470 & [MPa] \\
\hline \multicolumn{3}{|c|}{ Permitted pressure in the joint of a chain } \\
\hline Decisive pressure $(p)$ & 26.6 & \\
\hline Coefficient of friction $(\lambda)$ & 0.3 & \\
\hline$P_{0}$ & 7.98 & [MPa] \\
\hline
\end{tabular}

Figure 6. Unsuitable pressure

\subsection{Supporting Tables of the Program}

Since the chain program calculation requires several values being determined on the basis of the tables the program itself contains the parts in which the values can be sought for. The tables allow faster and easier calculation as should that be not the case the dictionary of engineering terms must be used. To facilitate the work, the following data and values were entered into the program [Pavlenko 2017a]:

- Coefficients of shock - in the program "selectable" in case of the offered option which can be opened and out of which the needed value can be selected. To determine the coefficient of shock correctly the program contains the table with descriptions referring to type of shock. Thus correct determination of its value is possible [Balazikova 2016]

- Coefficients of performance - other table of values refers to coefficient of performance which is selected according to number of teeth of the small chain wheel, gear ratio and coefficient of shocks [Mascenik 2016b].

- Coefficients of greasing - alike the coefficient of shock the coefficient of greasing can be selected out of the given values. To select correct value of the coefficient of greasing the program also contains the table with descriptions referring to its correct determination [Gaspar 2013].

- Decisive pressure of the joint - it refers to a table value which is selected according to operation time of the chain, coefficient of shock, coefficient of greasing, coefficient of axial distance and gear ratio. When the values have been detected, the decisive pressure can be read off the attached table of the program.

- Coefficients of friction - have been included into the table part of the program. To determine the value of coefficient of friction correctly, it is inevitable to determine coefficient of shock correctly, gear ratio, chain according to the standard, etc.

\section{CALCULATION EXAMPLE BY MEANS OF THE DESIGNED PROGRAM}

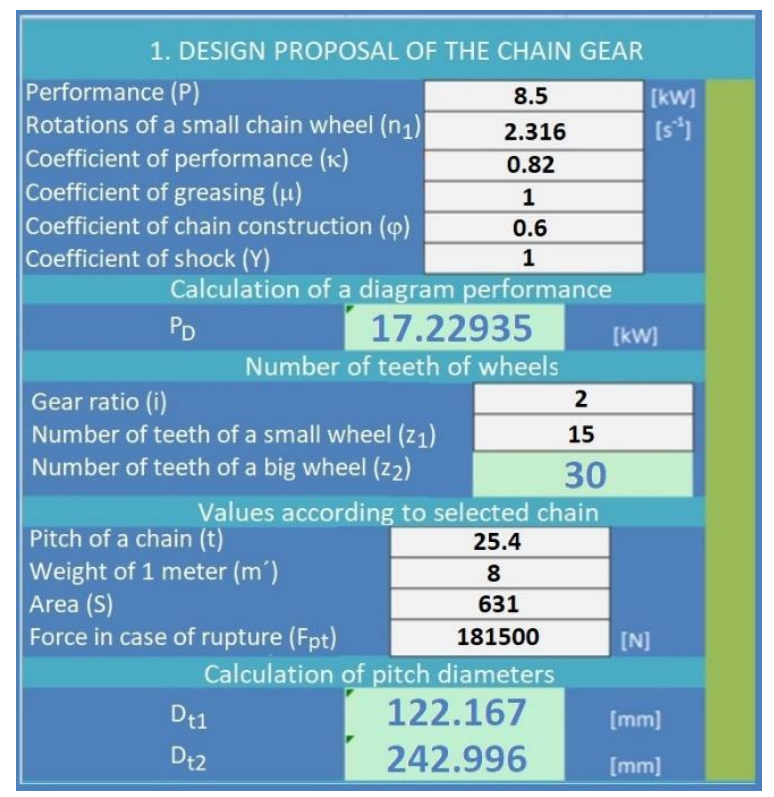

Figure 7. Designed Chain Gear

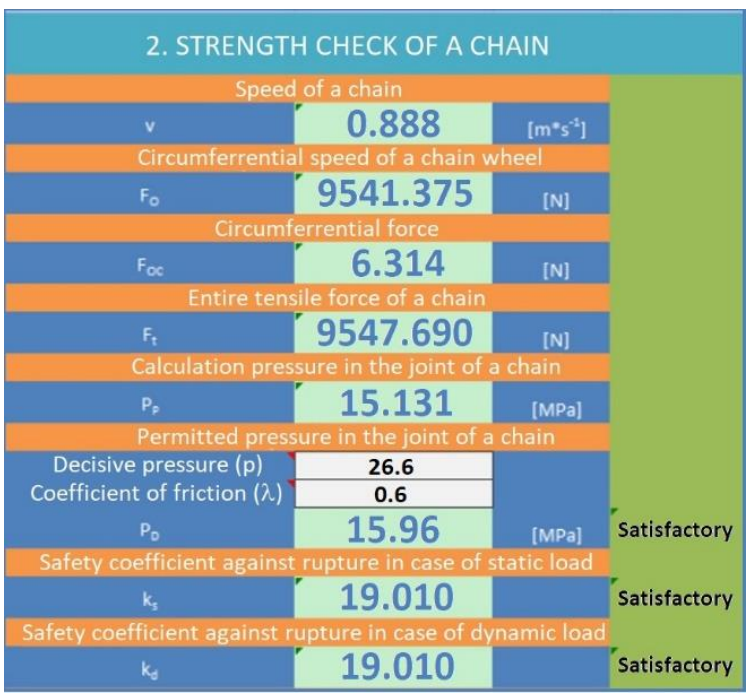

Figure 8. Strength check of chain gear $1 / 2$ 


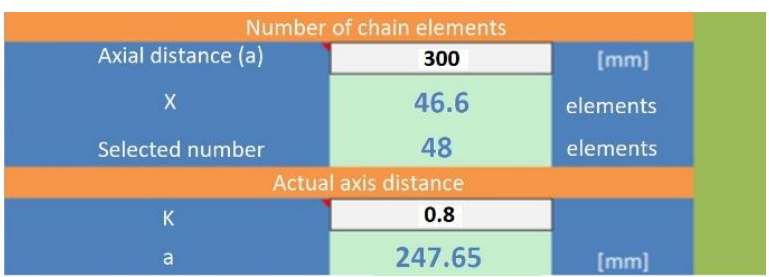

Figure 9. Strength check of chain gear $2 / 2$

\section{CONCLUSION}

When all inevitable values have been calculated by analytical calculation and by consequent calculation with the designed program the program might be considered as correctly designed since it generates results comparable with the design of chain gear and strength check of the selected chain. Contrary to analytical calculation the program appears to be rather advantageous and in case of inevitable calculations no calculators are needed which prevents incorrect entering of values. To simplify the calculation, the attached tables were used which shortened the period of searching for table values. Ultimately, the program thus facilitates work during calculations and assures their accuracy. Newly designed program can be applied in education process as well as in practice in development and production sphere.

\section{ACKNOWLEDGEMENT}

This article has been prepared within the project KEGA 051TUKE$4 / 2018$.

\section{REFERENCES}

[Balazikova 2016] Balážiková, M. Assessment of ergonomic risks of the selected work activity by niosh method. Science. Business. Society, 2016, Vol. 1, No. 5, pp. 42-45. ISSN 2367-8380.

[Bicejova 2013] Bičejová, L'. Abrasive kind and granularity changes affects to water jet technology head vibration during cutting HARDOX material thickness alternation process. Applied Mechanics and Materials, 2013, Vol. 308, pp. 75-79. ISSN 16609336.

[Cacko 2014] Cacko, P., Krenicky, T., Dobransky, J. Impact of an Excessive Wear of Bearing on the Mechatronic Devices. Applied Mechanics and Materials, 2014, Vol. 460, pp. 99-106. ISSN 16609336.

[Fabian 2014] Fabian, S., Bičejová, L'. Technological head tilt angle influence analysis to generation of vibration during ceramics material machining by means of AWJ technology.
Applied Mechanics and Materials, 2014, Vol. 616 pp. 175-182. ISSN 1660-9336.

[Gaspar 2017] Gašpár, S., Paško, J., Majerník, J. Influence of structure adjustment of gating system of casting mould upon the quality of die cast. Lüdenscheid, RAM Verlag, 2017, p. 82. ISBN 978-3-942303-47-7.

[Gaspar 2013] Gašpár, S. and Paško, J. Influence of technological factors of die casting on mechanical properties of castings from silumin. Lecture Notes in Electrical Engineering, 2013, Vol. 240, pp. 713-722. ISSN 1876-1100.

[Majernik 2018] Majerník, J., Gašpár, Š., Gryc, K., Socha, L. Changes in Eutectic Silumin Structure Depending on Gate Geometry and Its Effect on Mechanical Properties of Casting. Manufacturing technology, 2018, Vol. 18, No. 3, pp.439-443. ISSN 1213-2489.

[Mascenik 2014] Maščenik, J., Pavlenko, S. Aspects of alternative dispute creating bolted joint technology flowdrill. Applied Mechanics and Materials, 2014, Vol. 680, pp. 186-189. ISSN 1660-9336.

[Mascenik 2016a] Maščenik, J., Pavlenko, S., Bičejová, Ĺ. A device designed to monitor new belt types with application of diagnostic system. MM Science Journal, 2016, Vol. September, pp. 931-934. ISSN 1803-1269.

[Mascenik 2016b] Maščenik, J., Vojtko, I. Experimental monitoring and diagnostics of belt gears in testing device. MM Science Journal, Vol. 2016, No. September, pp. 964-968. ISSN 1803-1269, DOI: 10.17973/MMSJ.2016_09_201641.

[Murcinkova 2013] Murcinkova, Z., Krenicky, T. Applications utilizing the damping of composite microstructures for mechanisms of production machines and manipulator devices. In: SGEM 2013: 13th Int. Multidisciplinary Sci. Geoconf. Vol. 1: 16-22 June, 2013, Albena, Bulgaria. Sofia: STEF92 Technology, 2013, pp. 23-30. ISBN 978-954-91818-9-0.

[Pavlenko 2015] Pavlenko, S., Litecká, J., Maščenik, J., Kačalová, M. Gear Hobs Profiling and Gear Production Using Unconventional Technology, 2015, Brno MSD. 175 p. ISBN 97880-7392-249-8.

[Pavlenko 2017a] Pavlenko, S. Design and check of the mechanical components by the PC application. MM Science Journal. 2017, No. December, pp. 1914-1918. ISSN 1803-1269.

[Pavlenko 2017b] Pavlenko, S. Design of a program for calculation of forcing spring stiffness. MM Science Journal, 2017, No. December, pp. 1924-1928. ISSN 1803-1269.

[Smeringaiova 2016] Šmeringaiová, A., Vojtko, I., Lešková, B. Suspension system in automobile system. MM Science Journal, 2016, No. September, pp. 1004-1008. ISSN 1803-1269.

\section{CONTACTS}

M.Sc. Jozef Maščenik, PhD.

Department of Design and Monitoring of Technical Systems, Faculty of Manufacturing Technologies with a seat in Presov, Technical University of Kosice, Presov, Slovak Republic Bayerova 1, Presov, 080 01, Slovak Republic +421 51772 6337, jozef.mascenik@tuke.sk,www.tuke.sk 